\title{
Stable linear modulation of glow-modulator tubes
}

\author{
C. R. CAVONIUS and D. BAUER \\ Institut für Arbeitsphysiologie an der Universität Dortmund, D-4600 Dortmund 1, West Germany
}

\begin{abstract}
A circuit is described that permits modulation of the luminance of glow-modulator tubes with high accuracy and with no change in spectral distribution. Characteristics of a typical glow modulator are discussed in terms of its applications in visual research. Serious discrepancies were found between new measurements of spectral energy distributions and values that appear in the literature.
\end{abstract}

Glow-modulator tubes were common several decades ago in visual stimulators, but they now have fallen out of favor. As our experience with them has been satisfactory, and since we have received a number of inquiries for further information since describing their use in the measurement of visual sensitivity (Cavonius, 1979), we believe that it would be useful to describe some of their characteristics and to describe a circuit with which their output can be modulated.

Glow-modulator tubes as visual stimulators have been characterized as having poor stability, low intensity, and an unsatisfactory spectrum (Boynton, 1966). While each of these criticisms has some validity, glow modulators also have advantages. For one, they are still the only moderately priced source of broad-spectrum light that can be switched rapidly. However, in applications requiring modulation of intensity, they have the further drawback of nonlinearity. Not only is glow-modulator intensity an accelerating function of input current, but also, the hue of the resulting light changes from a desaturated orange to white as the current is increased.

Because of their rapid response (flat to $10 \mathrm{kHz}$, with a usable response at $1 \mathrm{MHz}$ ), glow modulators lend themselves to pulse-density or pulse-width modulation, which helps avoid the problem of nonlinearity. Pulsedensity modulation appeared to us to be safer, since all of the pulses are identical. It has the disadvantage that $100 \%$ modulation cannot be used because the individual pulses would be visible during the dark phase. However, for most practical purposes, a modulation of $95 \%$ is quite adequate; with an unmodulated carrier frequency of $5 \mathrm{kHz}$, the minimum frequency will be $250 \mathrm{~Hz}$, which is still well above critical flickerfusion frequency.

\section{GLOW-MODULATOR TUBES CIRCUIT}

The circuit described here was designed primarily for sinusoidal modulation, but it can be used to produce other patterns of temporal modulation or to control brightness by means of a dc signal. The main building block is a 4151 voltage-to-frequency converter

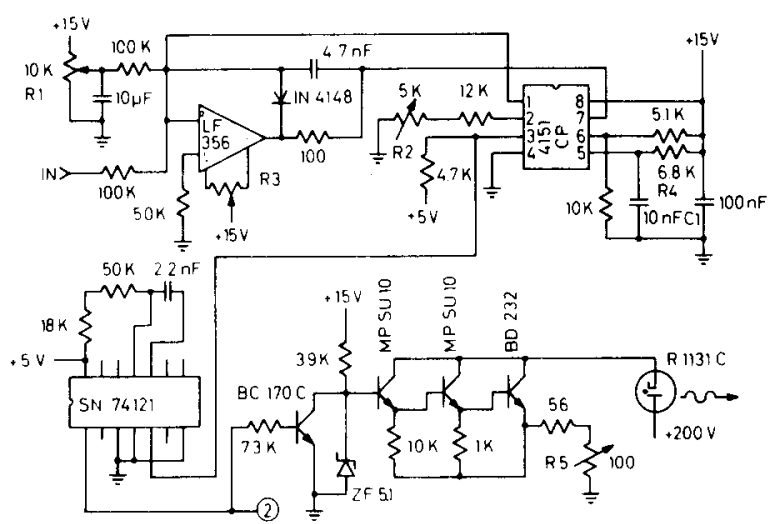

Figure 1. Circuit for pulse-density modulation of glowmodulator tubes. The power connections to Amplifier LF 356 are: Pin $4,-15 \mathrm{~V}$; Pin $7,+15 \mathrm{~V}$.

(VFC), which, in the circuit shown in Figure 1, gives a worst-case departure from linearity of $.52 \%$. This circuit requires an initial adjustment of range and offset, which is made by setting $R 1$ to $-10 \mathrm{~V}$ and $R 2$ so that it gives an output frequency of $10 \mathrm{kHz}$. R1 is next set to $-10 \mathrm{mV}$ and $\mathrm{R} 3$ is set to provide an output of $10 \mathrm{~Hz}$. Finally, R 1 is set to give the desired carrier frequency. We use $5 \mathrm{kHz}$, since we wish to modulate symmetrically about $0 \mathrm{~V} .{ }^{\prime}$

Since brightness depends upon pulse width as well as frequency, an adjustable one-shot was added after the VFC to permit small adjustments in brightness, by varying the $50 \mathrm{~K}$ resistor. If a fixed pulse width is sufficient, the pulse width of the internal one-shot in the $4151 \mathrm{can}$ be selected by the choice of $\mathrm{R} 4$ and $\mathrm{C} 1$; pulse width will be approximately 1.1 RC. However, because R4 and C1 also affect the output frequency, it did not seem to be advisable to adjust the brightness by changing R4.

The output stage is effectively a constant-current source, since the output current depends only upon the voltage at the input to this stage and the value of R5. Changes in the glow modulator have little effect. To avoid early lamp failure, R5 should be set so that not more than $25 \mathrm{~mA}$ flows through the lamp. The circuit 


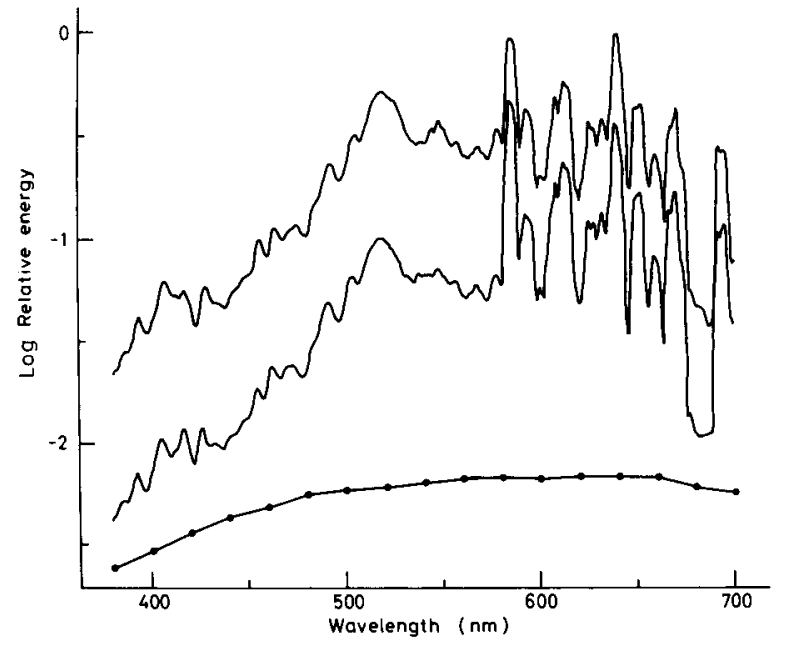

Figure 2. Logarithm of the spectral energy distribution of an $\mathrm{R}-1131 \mathrm{C}$ glow modulator, with a steady input of $25 \mathrm{~mA}$ (top curve) and $10 \mathrm{~mA}$ (middle curve). The combined sensitivity of the monochromator and detector is given by the bottom curve.

functions as a switch: When the input transistor is off, the output current is constant; when the transistor conducts, it short-circuits the diode and shuts off the lamp. We first tried to use feedback to stabilize the lamp current, but we gave up this approach because the circuit oscillated wildly when the lamp ignited. This can be avoided only by making the time constant of the circuit unacceptably long.

The output stage can be used in applications in which it is necessary only to switch the lamp on and off, as in a tachistoscope, by introducing TTL logic levels at Point 2. A multiple-channel tachistoscope can be built by placing one or more beam splitters before the eyepiece in a Maxwellian-view system (e.g., Westheimer, 1966; see Figure 2). Such a tachistoscope would be free of the problems of unintentional changes of color and $s$ timulus duration that are common in tachistoscopes that use commercial fluorescent tubes (Mollon \& Polden, 1978).

Because the frequency of the VFC depends strongly upon its supply voltage, this should be accurately stabilized. The Fairchild microampere $78 \mathrm{M} 15$ voltage regulator provides a convenient and inexpensive solution. The supply for the glow modulator must be robust enough to maintain its output when the tube is conducting.

The following tests may help prospective users to decide whether the glow modulator is suitable for a specific application.

\section{Stability}

Our experience cannot support the folklore that holds that glow modulators are unstable. During the first few minutes after being turned on, the light output increases rapidly by about $20 \%$, after which it falls back over about $15 \mathrm{~min}$ to a stable level, which remains constant to within $1.5 \%$ over many hours. When a glow modulator is fired frequently, as in pulse-density modulation, ignition appears to be very regular. However, if it is fired only infrequently, Matin (1964) suggests irradiating the tube with ultraviolet light to reduce time jitter in ignition.

\section{Spectral Distribution}

The spectral distribution of the R1131C glow modulator is worse than the spectrum that is given by the manufacturer (Sylvania, Note 1) and reprinted in the OSA Handbook of Optics (Zissis \& Larocca, 1978). We find that the relative energy at $400 \mathrm{~nm}$ is only about $10 \%$ of that shown in the published values and that there are many more peaks above $600 \mathrm{~nm}$. The data shown in Figure 2 were recorded with a double monochromator that had a total passband of $9 \mathrm{~nm}$ and a half-energy width of $6 \mathrm{~nm}$. While this smooths the spectrum considerably (e.g., the peak at $587 \mathrm{~nm}$ is actually a doublet, both members of which are more than $1 \log$ unit above their surround), we believe that this presentation is more realistic for visual stimulators, since monochromators and interference filters typically have bandwidths of $10-15 \mathrm{~nm}$. The raggedness of the spectrum means that if narrow-band filters are used to produce colored stimuli, it is important to calibrate the system with the same filters, since a small shift in the passband can cause a large change in luminous output.

A comparison of the spectra at 10 and $25 \mathrm{~mA}$ shows why the hue shifts from cream to white as brightness is increased: The peaks above $580 \mathrm{~nm}$ become less prominent, and the relative energy at short wavelengths is greater at $25 \mathrm{~mA}$.

\section{Brightness}

We have measured a luminous intensity of $.6 \mathrm{cp}$ directly in front of an R-1131C, driven with a steady current of $25 \mathrm{~mA}$. This is too low to be of much use in illuminating an extended field; but the bright source is ideally suited for Maxwellian-view optics, since it is small enough to image within the pupil. With a simple Maxwellian-view system, this gives a retinal illuminance of $1.5 \times 10^{5}$ td at $25 \mathrm{~mA}$, which is very bright indeed.

\section{Spatial Uniformity}

Although the bright crater of the R-1131C appears to be homogeneous, the envelope of the tube is very irregular. Because the source of light is small, the envelope casts shadows when the tube is used to illuminate directly a uniform surface, resulting in at least a $2: 1$ ratio of brightness in different regions. Fortunately, the envelope is so close to the source that in Maxwellian- 
view applications its image is almost in the plane of the pupil, and therefore, it does not cause noticeable inhomogeneities.

\section{REFERENCE NOTE}

1. Sylvania. Glow modulator tubes (GTE Sylvania Technical Data Service Report No. TR-29-R-1). Salem, Mass: Author, 1972.

\section{REFERENCES}

Boynton, R. M. Vision (Chap. 7). In J. B. Sidowski (Ed.), Experimental methods and instrumentation in psychology. New York: McGraw-Hill, 1966.

Cavonius, C. R. Binocular interactions in flicker. Quarterly Journal of Experimental Psychology, 1979, 31, 273-280.

Matin, L. On the use of glow modulator tubes for visual research. American Journal of Psychology, 1964, 77, 650-651.
Mollon, J. D., \& Polden, P. G. On the time constraints of tachistoscopes. Quarterly Journal of Experimental Psychology, $1978,30,555-568$.

Westheimer, G. The Maxwellian view. Vision Research, 1966, 6, 669-682.

Zissis, G. J., \& Larocca, A. S. Optimal radiators and sources. In W. G. Driscoll \& W. Vaughn (Eds.), Handbook of optics. New York: McGraw-Hill, 1978.

\section{NOTE}

1. Further information and applications are cited in the Ray theon Company, Fairchild Company, and Exar Corporation data sheets for the 4151 VFC, from which this circuit was adapted.

(Received for publication December 4, 1981; accepted December 21, 1982.) 